\title{
An EASO Goal Achieved! OBESITY Facts Launched as Official Journal of EASO
}

\author{
Vojtech Hainer ${ }^{\mathrm{a}}$ Euan Woodward ${ }^{\mathrm{b}}$ \\ aEASO President, Obesity Management Centre, Institute of Endocrinology, Prague, Czech Republic \\ ${ }^{\mathrm{b}}$ EASO Executive Director, EASO Secretariat, London, UK
}

The European Association for the Study of Obesity (EASO) is delighted that OBESITY FACTS has been launched as an official journal of EASO. The question 'Why publish another new scientific journal on obesity?' has been partly answered in the Editorial by Johannes Hebebrand. So, why have we launched OBEsITY FACTS as a European journal?

The existing portfolio of international journals specialising in obesity cannot provide enough space for publishing the results of the growing level of worldwide obesity research. In response to this rising number of obesity studies, regional obesity associations in North America and Asia Oceania have launched their own obesity journals. Europe is a continent characterised not only by a high prevalence of obesity but also by a rapidly growing obesity research environment yet the European Association for the Study of Obesity has remained until 2008 without its own specialised journal. The idea to establish such a journal was raised almost 3 years ago and OBEsITy FACTS now fulfils a long standing ambition of the Association.

Obesity was a rather rare entity until the 20th century when at the turn of the millennium it had reached epidemic proportions globally. Prevalence of obesity in Europe is quite high, ranging from 10 to $20 \%$ in men and from 15 to $30 \%$ in women. In several European countries it has almost doubled during the past two decades, and the continually increasing prevalence of obesity in children is alarming. Approximately $20 \%$ of European children are overweight or obese. However, childhood rates for overweight and obesity in southern Europe exceed $30 \%$, a figure comparable to that in the USA.

It is not surprising that in response to the rising prevalence of obesity, more and more attention has been paid to the problems of obesity by both researchers and clinicians. The enhanced focus on obesity has been reflected in a growing number of publications on obesity. Using the search term 'obesity' with PubMed, 46,000 citations on pathogenesis, 49,000 on treatment, 25,000 on prevalence, 13,000 on prevention and 6,000 on health risks of obesity were retrieved. Do we therefore really need a new European journal on obesity? There is a current trend for splitting medical entities into separate subdisciplines. In contrast to this, obesity, as a new and rather young medical discipline, has succeeded in returning to a holistic approach. The modern concept in both obesity research and clinical practice covers a broad field of biomedicine including genetics, internal medicine, psychology, psychiatry, endocrinology, nutrition, exercise physiology, anthropology, pharmacology, bariatric surgery, epidemiology and social studies etc. We believe that this new journal will fully reflect this multidisciplinary character of obesity. It will fill a gap among obesity journals and provide a platform which will attract both recognised and new European and international scientists to publish their articles reflecting recent advances in obesity research.

As pointed out by the Editor-in-Chief, the title of the journal 'facts' does not exclude scientific fiction. However, we should take into account what Hans Selye emphasized on the opening page of his book on stress (1950): 'Our facts must be correct. Our theories need not be if they help us to discover important new facts'. In order to ensure scientific correctness, the papers for publication in OBESITY FACTS will be selected solely based on scientific quality as assessed by international peer reviewers.

We would also like to provide the readers with some information on the EASO. EASO was established to promote research into obesity and to develop actions in obesity prevention and management that tackle the epidemic of obesity, as well as to facilitate contacts between individuals and organisations. EASO was founded in 1988 when the first European Congress on Obesity was held in Stockholm. This means that EASO celebrates its 20th anniversary this year. At the age of 20 , new horizons open for a young adult human as at this age a

\begin{tabular}{ll}
\hline KARGER & $\oplus$ 2008 S. Karger GmbH, Freiburg \\
$\begin{array}{l}\text { Fax +497614520714 } \\
\begin{array}{l}\text { E-mail Information@Karger.de } \\
\text { www.karger.com }\end{array}\end{array}$ & $\begin{array}{l}\text { Accessible online at: } \\
\text { www.karger.com/ofa }\end{array}$
\end{tabular}

\section{KARGER}

E-mail Informat
www.karger.com
Prof. Dr. Vojtech Hainer

Obesity Management Centre

Institute of Endocrinology

Narodni 8, 11694 Prague 1, Czech Republic

E-mail vhainer@endo.cz 
professional career or university studies usually begin. For a 20-year-old EASO, new horizons are also opening with the launch of OBESITY FACTS as The European Journal of Obesity. During the last two decades EASO has experienced a significant growth in membership and activities. Currently EASO has 28 member associations covering almost 4,000 members in 29 countries. Members are recruited from a wide range of professions, including physicians, dietitians, psychologists, exercise physiologists, basic scientists etc. To date, 15 European Congresses on Obesity (ECO) have been organised by EASO. Recent congresses have been characterised by increasing attendance (more than 2,500 participants) and number of presentations (more than 800 abstracts). EASO focuses not only on organising congresses but contributes to educational activities at both international and national level. EASO is actively involved in the international SCOPE project (Specialist Certification of Obesity Professional Education) which was originally designed for Europe. In 2001, EASO established three task forces: one on Obesity Management, one on Public Health, and one on Childhood Obesity. Since its establish- ment, the Obesity Management Task Force has conducted two surveys on obesity management in European countries and prepared comprehensive guidelines on the 'Management of Obesity in Adults: Project for European Primary Care' and, in collaboration with the European bariatric surgeons, 'Interdisciplinary European Guidelines on Surgery of Severe Obesity'. Updated versions of both guidelines will be soon available for readers of OBESITY FACTS. EASO is also engaged in European initiatives on obesity prevention, and we believe that members of the EASO task forces could provide a valuable contribution to both publication activities and the reviewing process for the new journal. An EASO group of the new investigators, Young Investigators United, creates links between young scientists involved in obesity research throughout Europe, and this group also will appreciate increased publication opportunities offered by the launch of OBEsITY FACTS. We are sure that OBESITY FACTS, as an official journal of the EASO, will provide a wide platform for obesity research as well as for experiences from clinical practice in Europe. 